FONTES PCR. 2014. Nutrição mineral de hortaliças: horizontes e desafios para um agrônomo. Horticultura Brasileira 32: 247-253. DOI - http://dx.doi. org/10.1590/S0102-05362014000300002

\title{
Nutrição mineral de hortaliças: horizontes e desafios para um agrônomo
}

\author{
Paulo CR Fontes \\ UFV, Depto. Fitotecnia, 36571-000 Viçosa-MG; pacerefo@ufv.br
}

\section{RESUMO}

Nutrição mineral busca entender a complexa interação entre o inorgânico e o orgânico: a vida vegetal. Enumero alguns exemplos de temas e assuntos momentâneos relacionados à área de Nutrição Mineral em interfaces com diversas áreas do conhecimento e que podem ocorrer ao nível de molécula, célula, tecido, órgão e planta inteira. Procuro no presente texto enfocar as competências ou os atributos exigidos ao engenheiro agrônomo na atual "sociedade do conhecimento". Adicionalmente, procuro pincelar um tema atual de Nutrição Mineral que trata da avaliação e diagnose do estado de nutrientes das plantas, especialmente de nitrogênio, em tempo real, tema que tenho concentrado os meus últimos trabalhos. Para diagnosticar a deficiência mineral que a planta tem é fundamental conhecer a planta que tem a deficiência. Ao se realizar o diagnóstico nada é absolutamente certo até ser comprovado. Pelo diagnóstico não é possível determinar a quantidade requerida de nutrientes, mas o estado de nutrientes da planta no momento da amostragem, ou seja, a necessidade ou não de adubar a cultura com determinado nutriente. Após a diagnose há procedimentos para estimar a dose do fertilizante. A ação contínua à diagnose deve ser a recomendação ou a prescrição do programa de adubação da cultura seguida de aferição da mesma em termos de porcentual de acerto, ganho econômico e preservação ambiental. Tais procedimentos precisam ser realizados de forma sistêmica e acoplados ao sistema de produção acertado com o produtor/olericultor.

Palavras chave: Engenheiro agrônomo, nutricionista de planta, diagnose, campo de ação, competências, habilidades, conhecimento.

\begin{abstract}
Mineral nutrition of vegetable crops: horizons and challenges for an agronomist

Mineral nutrition seeks to understand the complex interaction between the inorganic and organic: plant life. I enumerate some examples of topics and issues related to the Mineral Nutrition area on interfaces with various knowledge fields that can occur at molecule, cell, tissue, organ, and whole plant level. I try to focus this text on the skills or attributes required to an agronomist in the current "knowledge society". Additionally, I try to point out a current Mineral Nutrition issue dealing with the evaluation and diagnosis of the plant nutritional status, especially towards nitrogen, in real time, an issue that I have focused my latest works. A reasonable knowledge of the plant studied is crucial for diagnosing their mineral deficiencies. Nothing is absolutely right until the diagnosis is proven. The plant nutrient status at sampling, that is, defining whether or not to apply a certain nutrient to the crop at that moment, is possible to be determined by the diagnosis process. The required amount of nutrients for the crop, however, cannot be determined by this process. Procedures are carried out after diagnosis for estimating the fertilizer rate. The actions following diagnosis should be recommendation or prescription of the crop fertilization program followed by this assessment in percentage of correct actions, economic gain and environmental preservation. Such procedures must be performed in a systematic way and coupled to the production system adjusted with the producer.
\end{abstract}

Keywords: Agronomist, plant nutrition, diagnosis, action field, skills, abilities, knowledge.

\section{(Recebido para publicação em 4 de março de 2014; aceito em 3 de junho de 2014) (Received on March 4, 2014; accepted on June 3, 2014)}

\begin{abstract}
A razão deste texto foi a pergunta de um antigo amigo melhorista: "ainda são feitos trabalhos na área de nutrição e adubação de hortaliças"? Refleti um pouco, pensei e tento responder a esse amigo. A busca de informação sobre o efeito de nutrientes no desenvolvimento das plantas vem desde a época em que foi observado que a adição de esterco e restos de animais promovia o aumento na produtividade das culturas. Em 1650, a água era considerada como o principal nutriente para as plantas (Nortcliff \& Gregory, 2013). Segundo os
\end{abstract}

autores, a primazia da água foi questionada em 1699 por Woodward que mostrou que as plantas de menta cresceram mais em águas impuras. A busca por maior conhecimento sobre os nutrientes para as plantas aconteceu a partir de 1750 . Em 1840, Liebig publicou "Química e suas aplicações na agricultura e fisiologia" que acenou para um repensar que "as colheitas no campo diminuem ou aumentam na proporção exata da diminuição ou aumento das substâncias minerais..." (Nortcliff \& Gregory, 2013). Daí para frente, os estu- dos envolvendo solo $\mathrm{x}$ plantas $\mathrm{x}$ nutriente (Nutrição Mineral) foram incrementados e associados com outros campos da ciência.

Nutrição Mineral de plantas é a área do conhecimento envolvida com o estudo dos elementos químicos necessários à planta para complementar o seu ciclo. A área pode ser considerada sob diversas perspectivas dentre as quais a perspectiva fisiológica, genética, bioquímica, ecológica e agrícola. Isso é, há acentuada inserção e interface com outras áreas do conhecimento. A nutrição mineral é 
tópico importante em ecologia, genética, biologia e agronomia pela necessidade de ligação entre o ionoma com fatores adaptativos, genéticos, metabólicos e de manejo das plantas. É uma área que busca entender a complexa interação entre o inorgânico e o orgânico: a vida vegetal.

A área de Nutrição Mineral vai do nível de molécula passando por célula, tecido, órgão e chega à planta inteira; busca entender diversos processos desde o funcionamento de membranas até o crescimento de um conjunto de indivíduos; procura estudar aspectos sobre o transporte, mobilidade e metabolismo dos íons em células e plantas além de compreender aspectos ecológicos, fisiológicos, bioquímicos e genéticos da nutrição da planta.

Também, a Nutrição Mineral trata de aspectos práticos da produção tanto em solo quanto em hidroponia procurando desenvolver técnicas para cultivar plantas em solução nutritiva e solo, envolvendo aspectos teóricos e práticos do manejo dos fertilizantes nas plantas. Mais ainda, a Nutrição Mineral trata das complexas interações iônicas, teóricas e complexas, nos diversos níveis da planta e também busca estabelecer índices para o diagnóstico do estado de nutrientes e entender modificações quantitativas e simultâneas da composição de elementos químicos na planta por influência de algum fator (ionômica).

A "metade escondida da planta", a raiz, adquire, absorve, regula e transporta os nutrientes de forma integrada com a outra metade, a parte aérea, em processos extremamente bem coordenados, mas ainda pouco conhecidos. Esses processos bem ajustados envolvendo aspectos da demanda, disponibilidade, aquisição, absorção, regulação, transporte, distribuição, assimilação, utilização, acúmulo e remobilização dos nutrientes são partes integrantes da tarefa de um nutricionista mineral, possível de ter formação básica em diversas áreas como biologia, bioquímica, agronomia, floresta entre outras.

Além da formação básica, um pesquisador "nutricionista de planta" precisa concentrar-se em algum aspecto pontual, ter especialidade ou especificidade no trabalho. Há cada vez menos espaço para generalista. Mas sempre é necessário ter em mente que a molécula, célula, tecido e órgão estudados isoladamente fazem parte de uma "planta inteira" que deverá ser útil a algum ser vivo.

Devido ao elevado número de especialidades envolvidas, há momentos onde os detalhes metodológicos são tão específicos e demandadores de equipamento e técnicas específicas que mesmo os profissionais de áreas conexas sentem dificuldades no entendimento seguro do tema tratado no trabalho.

Procuro no presente texto enfocar as competências ou os atributos exigidos ao agrônomo na atual "sociedade do conhecimento". Adicionalmente, procuro pincelar um tema atual de Nutrição Mineral que trata da avaliação e diagnose do estado de nutrientes das plantas, especialmente de nitrogênio, tema que tenho concentrado os meus trabalhos nos últimos anos.

A nutrição mineral de plantas envolve diferentes processos relacionados aos nutrientes, como por exemplo: a) demanda da planta; b) disponibilidade no solo; c) interação das raízes e organismos do solo na aquisição dos nutrientes; d) absorção; e) transporte; f) distribuição; g) assimilação; h) utilização; i) acúmulo; j) remobilização. Tais etapas necessitam ser contextualizadas e integradas ao programa de manejo da adubação e do sistema de produção da hortaliça pelo agrônomo, via os existentes conhecimentos de nutrição mineral, pois sofrem forte efeito da interação clima-solo-genótipo-horticultor. Isso exige postura sistêmica, caso o objetivo seja de aumentar a eficiência do uso dos nutrientes e, concomitantemente, a lucratividade da produção de hortaliças.

\section{Nutrição mineral: segmentos}

Os nutrientes químicos necessários para a planta produzir adequadamente são os focos da área de Nutrição Mineral. Atualmente, os elementos essenciais para as plantas são: carbono $(\mathrm{C})$, oxigênio $(\mathrm{O})$, hidrogênio $(\mathrm{H})$, nitrogênio $(\mathrm{N})$, fósforo $(\mathrm{P})$, potássio $(\mathrm{K})$, cálcio $(\mathrm{Ca})$, magnésio $(\mathrm{Mg})$, enxofre $(\mathrm{S})$, boro $(\mathrm{B})$, ferro $(\mathrm{Fe})$, cobre $(\mathrm{Cu})$, manganês $(\mathrm{Mn})$, zinco $(\mathrm{Zn})$, cloro $(\mathrm{Cl})$, níquel $(\mathrm{Ni})$ e molibdênio (Mo).

Para efeito didático, costumo dividir a área de nutrição de plantas em dois segmentos que abarcam temas teóricos e práticos. O primeiro segmento busca conhecimento aplicado sobre os proces- sos que afetam a função e as perdas de nutrientes aplicados como adubos utilizados no crescimento, desenvolvimento e produção das plantas. Esse segmento, fortemente associado às áreas de Solos, Fisiologia Vegetal e Produção Vegetal ou Fitotecnia (é preciso lembrar que há necessidade de "saber plantar"), busca o desenvolvimento de recomendação, produto, equipamento, procedimento, rotina, instruções ou algo similar, obviamente calcado em conhecimento teórico, relacionado aos nutrientes na planta.

De forma acentuada, no segmento aplicado, os trabalhos buscam o manejo dos nutrientes minerais no sistema solo-planta-ambiente-genótipo calcados na busca da eficiência do uso dos nutrientes pelas espécies e com a perspectiva da aplicabilidade prática, racionalidade econômica, sustentabilidade e segurança na produção das plantas.

Quase sempre, nessa área "prática ou aplicada", os trabalhos não propiciam resultados considerados de interesse dos periódicos considerados como A1. Não entendo bem as variáveis utilizadas para classificação dos periódicos. Ao que me parece, periódico de nenhuma Sociedade Brasileira ligada à agricultura está classificado como A1. Infelizmente, "aparenta ter restrito valor" científico. Conclusão limitada e restritiva. Que pena e incoerência, pois a agricultura/olericultura brasileira são tão desenvolvidas e eficientes no campo. Obviamente, com peculiaridades locais, regionais ou nacionais que ao longo de cinqüenta anos temos sabido ajustar. Talvez, o meu mestre, professor Janick (2008), consiga explicar, mas eu continuo não entendendo.

O segundo segmento envolve a busca do entendimento básico e do conhecimento teórico nos processos envolvendo demanda; disponibilidade; aquisição, absorção; regulação; transporte; distribuição; assimilação; utilização; acúmulo e remobilização dos nutrientes. Esse segmento tem forte inserção em áreas do conhecimento como Fisiologia Vegetal, Bioquímica, Biofísica, Sensoriamento de imagens e diversas outras áreas.

Enumero alguns exemplos de temas e assuntos momentâneos relacionados à área de Nutrição Mineral em interfaces com diversas aéreas do conhecimento (Tabela 1) e que podem ocorrer ao nível 
Tabela 1. Exemplos de temas e assuntos relacionados ao campo da Nutrição Mineral em interfaces com outras áreas (examples of topics and subjects related to the Mineral Nutrition field on interfaces with other areas of knowledge). Viçosa, UFV, 2013.

\section{Alguns temas e assuntos relacionados à área de Nutrição Mineral}

Aquisição de nutrientes pelas raízes e propriedades e organismos do solo

Aspectos ecológicos da nutrição de plantas

Compartimentalização celular na nutrição da planta

Desenvolvimento de nanobiossensores de nutrientes

Detecção e sinalização de nutrientes

Eficiência de aquisição, absorção e assimilação de nutrientes

Eficiência do uso dos nutrientes: bases fisiológicas, moleculares e agronômicas

Estrutura das proteínas das membranas e a absorção de nutrientes

Fixação de nitrogênio

Funções fisiológicas dos transportadores e dos canais iônicos

Integração crescimento da planta, hormônios e nutrientes

Interações entre nutrientes no solo e nas plantas e bioinformática

Mecanismos internos de alocação, uso, reabsorção e reciclagem dos nutrientes

Mecanismos moleculares e respostas das raízes na aquisição dos nutrientes

Melhoramento para características nutricionais: fitonutrientes e biofortificação

Metabolismo dos ionomes (ionômica) com enfoque sistêmico do mRNA (transcriptômica), metabolitos (metabolômica) e enzimas

Mobilização iônica, balanço ácido:base na rizosfera e microorganismos

Nutrientes como sinalizadores intracelulares e regulação do desenvolvimento da parte aérea-raiz

Nutrientes e rizobactérias promotoras de crescimento

O papel osmótico dos nutrientes nas plantas

Predição da adubação nitrogenada pela análise da planta

Rede controladora da absorção de nutriente, metabolismo e desenvolvimento da planta

Redes regulatórias do estresse abiótico como a salinidade

Regulação de transporte de macronutrientes na planta

Sensoriamento remoto e proximal na avaliação do estado de nutrientes das plantas

Sistema de chip elétrico-mecânico de diagnóstico: "Lab On a Chip"

Tolerância das plantas ao estresse salino

de molécula, célula, tecido, órgão e planta inteira (Marschner, 1995; Masclaux et al., 2001; Cakmak, 2002; Hermans et al., 2006; Hirel et al., 2007; Hoefgen \& Nikiforova, 2008; Malavolta, 2008; Salt et al., 2008; Amtmann \& Armengaud 2009; Mounicou et al., 2009; Urano et al., 2010; Vinothkumara \& Hendersona, 2010; Hawkesford \& Barraclough, 2011; Krouk et al., 2011; Kusano et al., 2011; Silva et al., 2011; Von Wirén, 2011; Chapman et al., 2012; Cui, 2012; Monshausen, 2012; Puig et al., 2012; Schachtman, 2012; Xu et al., 2012; Gregory \& Nortcliff, 2013; Martin, 2013; Rengel, 2013; Usha \& Singh, 2013). Dezenas de outros temas poderiam ser citados, pois Nutrição Mineral busca entender a complexa interação entre o inorgânico e o orgânico: a vida vegetal.

Independentemente de divisão, não pode ser desprezado e desconsiderado por nenhum profissional, principalmente o agrônomo que a planta é organizada, vive de forma integrada, sinergística e coordenada em si como moléculas, organelas, células, tecidos e órgãos. Adicionalmente, nas formas individual e em conjunto, as plantas estão sob uma determinada interação genotípica, edafo-climática e de manejo humano, provavelmente única. Mas, o mais importante na minha ótica é que as plantas necessitam produzir algo essencial à vida heterotrófica com lucratividade e sustentabilidade. Para isso, há a necessidade do conhecimento gerado nos dois segmentos acima citados, possível de ser entendido e aplicado por um agrônomo.

Nutrição mineral: avaliação e diagnose

O convívio nos meios acadêmico, técnico e profissional, favorece a percepção de que tanto alunos quanto profissionais ligados à área de agronomia demonstram dificuldades em entender o termo diagnóstico do estado nutricional de plantas. O mesmo ocorre nos textos escritos. Há intercâmbio entre os termos diagnóstico $\mathrm{x}$ análise foliar x avaliação x interpretação $\mathrm{x}$ laudo. Às vezes os termos parecer ou laudo são imperfeitamente usados como sinônimos de diagnóstico. Os mesmos devem ser referidos como o produto final da diagnose. Também, de forma mais do que imperfeita, os termos recomendação e prescrição são usados como sinônimos de diagnóstico.

Diagnosticar é termo comum em várias disciplinas. Costuma ser entendido como avaliar e conhecer (ou construir o conhecimento) sobre um problema com alta probabilidade de acerto, visando propor solução para o mesmo. O termo 
diagnosticar o estado nutricional de plantas costuma ser usado como sinônimo de avaliar o estado nutricional de plantas e de interpretar o resultado da análise foliar. É necessário o entendimento sobre esses que, às vezes, são utilizados como sinônimos, mas deveriam ser empregados com significados distintos (Fontes, 2011). De fato são termos interligados, mas é entendido que os mesmos possuem diferentes significados. Além da avaliação do estado nutricional de plantas, via as várias possíveis análises, dentre as quais a análise foliar, diagnosticar é um processo que deve envolver procedimentos complementares. De outra forma, pode-se incorrer na interpretação de resultados numéricos e não em diagnose.

Diagnosticar o estado nutricional de plantas é emitir parecer (sim ou não) sobre a hipótese formulada de possível deficiência ou de toxidez de nutriente na amostra de plantas analisadas (representativa de uma população). Essa hipótese necessita ser calcada em adequadas análises das condições climáticas, edáficas e da planta, além das possíveis interações entre as mesmas, sem contar os procedimentos e ações do olericultor. Tarefa difícil. Na diagnose são utilizados diferentes exames na busca de dados e informações para serem relacionados com lógica de causa e efeito. Diagnosticar exige postura investigativa baseando-se em conhecimento, fatos e experiência do técnico. A esses se somam intuição, probabilidade, humildade, diálogo, postura de detetive, comunicação e senso de observação local para contextualizar os resultados das análises. Há sempre espaço para aprender, aperfeiçoar e ganhar experiência neste tópico que envolve ciência e percepção.

Diretamente ou por eliminação, a diagnose envolve a relação de causa e efeito de fatores envolvidos na absorção, translocação e utilização dos nutrientes onde são buscadas evidências sobre deficiência ou, menos comumente, toxidez mineral. Nestes casos pode ocorrer tanto o aparecimento dos sintomas clássicos quanto o de sintomas não aparentemente perceptíveis. Sintomas clássicos de deficiência costumam ocorrer quando a planta recebe quantidade mínima de fertilizante, hipótese pouco provável em empreendimento comercial. Entretanto, a percepção de sintomas não clássicos ou subliminares de deficiência ou de toxidez mineral pode ser difícil para os profissionais e possíveis de ocorrerem em olericultura. Em solo não é comum o aparecimento de sintomas visíveis de excesso ou de toxidez de macronutrientes.

A avaliação do estado de nutrientes das plantas é comumente realizada pela análise foliar. Esse é um método direto usado para determinar quantitativamente os nutrientes na matéria seca da folha, sendo ferramenta auxiliar no processo de diagnosticar o estado de nutrientes da planta. Adicionalmente, há menção do uso da análise foliar para monitorar o programa de adubação sem a aparente perspectiva de resolução do problema na safra vigente. Tratando-se de planta anual, a análise foliar provavelmente fornecerá informação possível de ser usada somente no ano seguinte. Tal enfoque tem diminuído de importância nas plantas anuais, principalmente no caso do nitrogênio, em favor da diagnose em tempo real, em momento que ainda seja possível corrigir o problema detectado. Para os demais nutrientes, macro e micro elementos, a análise do solo ainda tem utilidade podendo-se especular que o desenvolvimento de método de avaliação dos mesmos na planta em tempo real seja uma perspectiva de futuro.

Os valores quantitativos obtidos na análise foliar podem ser simplesmente interpretados por variados procedimentos, mais usualmente utilizando-se padrões tabelados como referências. Isso deve ser chamado de interpretação do resultado da análise foliar. Usar a análise foliar com o enfoque de interpretar número tem limitado valor como ferramenta de manejo do programa de fertilização da cultura, principalmente das culturas anuais. Tal enfoque tem utilidade em estudos comparativos de mecanismos de absorção, translocação, utilização e interações dos nutrientes na planta, em função de diferentes tratamentos, quase sempre envolvendo o uso de fertilizantes.

Quando o resultado da análise foliar é associado à anamnese de planta-problema, normalmente realizado por questionário genérico para todas as espécies, preenchido sem precisão e com limitado conhecimento teórico, no momento da entrega da amostra ao laboratório, o resultado de tal procedimento pode ser chamado de avaliação do estado de nutrientes das plantas. Com esse enfoque, a análise foliar é ainda de utilidade limitada.

Quando o resultado da avaliação do estado de nutrientes das plantas, incluindo-se o resultado da análise foliar é precedido e associado às apropriadas anamneses do sistema de produção e de plantas-problemas e de informações oriundas das análises física e química do solo, tal procedimento pode ser chamado de diagnóstico (Fontes, 2011). Com esse enfoque, a análise foliar tradicional é útil, principalmente em plantas perenes. Em plantas anuais, a utilidade do diagnóstico será maior caso a análise seja realizada em tempo real, ensejando a resolução do problema nutricional na safra ainda vigente.

A análise foliar é uma análise direta, ou seja, é estimada a existente concentração do nutriente no tecido (avaliação da composição mineral). A aparente concentração dos nutrientes pode ser realizada pela análise visual. Enquanto a avaliação visual é realizada em tempo real, no campo, a concentração existente normalmente é determinada em tecido seco, em laboratório ou, menos comumente, no suco celular. A metodologia clássica de avaliação do estado de nutrientes é a análise do teor do nutriente na matéria seca da folha.

Nas análises indiretas de avaliar o estado de nutrientes das plantas procura-se utilizar uma característica ou índice ou bioindicador cujo valor seja correlacionado com a concentração do nutriente na planta. Alguns exemplos de análises indiretas são a avaliação da intensidade da presença de polifenóis nos tecidos, reações enzimáticas ou bioquímicas, intensidade do verde da folha, características biométricas da folha e da planta e índices de refletância ou de energia irradiada da folha e da planta.

A avaliação do estado de nutrientes das plantas envolve observações, técnicas, procedimentos, leitura de cor, equipamentos, programas de computador, imagens obtidas com câmeras digitais, proximais ou orbitais em satélites entre outras. Cada uma com metodologia específica que precisa ser eficaz, rápida, 
sensível, de baixo custo e que seja viável de ser inserida na rotina de trabalho. Quando destinada para utilização em grande extensão de área a metodologia deve ser automatizada. A avaliação do estado de micronutrientes na planta cada vez é mais necessária, principalmente em tempo real, mas é escasso o relato de procedimentos eficazes sobre o tema.

Em consonância com a agricultura de precisão, a análise do estado de nitrogênio das plantas em tempo real, mesmo que possa ser menos sensível e específica do que a metodologia padrão, realizada em laboratório, vem crescendo em importância. Esse tema vem sendo enfaticamente estudado nos últimos anos por diversos grupos de pesquisa em todo mundo. Nessa linha tem havido estudos focados em diversos tipos de análises como teores dos nutrientes na seiva, polifenóis, clorofilas, intensidade da cor verde da folha, características biométricas da planta, imagens digitais e índices de refletância determinados por diversos procedimentos e equipamentos portáteis que utilizam a fluorescência e a transmissão da luz da folha como o clorofilômetro, o medidor de nitrato na seiva, a câmera digital, a tabela de cor, a fita métrica e as imagens digitais (Fontes, 2011). As análises visando determinar o estado de nitrogênio em tempo real é a tendência atual de abordagem em consonância com a tecnologia de dose variada, parte integrante da agricultura de precisão.

Com o desenvolvimento e evolução dos métodos de análise, que têm avançado para o nitrogênio, o diagnóstico do estado nutricional de plantas em tempo real passa a ser usado como ferramenta auxiliar na decisão de aplicar o adubo em cobertura (s). Isto é, o diagnóstico incorpora-se ao manejo preciso do programa de adubação da cultura ou sintonia fina da recomendação.

Diagnose precoce do estado nutricional de plantas anuais

Há situações nas quais é possível precocemente visualizar plantas apresentando problema nutricional. Há também situações onde há o problema, não visível ao olho humano, mas possível de ser detectado precocemente, por determinado procedimento. O olericultor experiente tem uma percepção aguçada de que "algo não está indo bem em sua lavoura". A linha de detecção precoce de deficiência ou de insuficiência, seja no trabalho de campo e/ou na investigação científica, bem mais avançada na medicina, é um caminho promissor em olericultura.

No caso da tentativa de percepção precoce de problema nutricional, as análises de solo e de folha de planta-problema e normal no mesmo estádio de crescimento podem propiciar diagnóstico utilizável na mesma safra (Fontes, 2011). Esse procedimento em plantas anuais pode ser denominado de diagnose precoce estando associado à possibilidade de realizar medidas corretivas na safra atual ou em momento quando ainda é possível e econômico corrigir possível deficiência mineral. A olericultura irrigada por gotejamento é uma ótima cliente para esse tipo de procedimento.

A avaliação precoce pode também ser usada com restrições como ferramenta de prognóstico de alguma característica que ocorrerá na futura colheita, tais como produtividade, teor de proteínas na semente, teor de matéria seca nos tubérculos, entre outros. Prognosticar a produção é ter conhecimento antecipado da mesma e vem sendo proposto, pois é conhecimento útil no estabelecimento de algoritmo destinado a estimar a dose de adubo a aplicar em cobertura além de permitir o planejamento de medidas gerenciais na cultura (Fontes, 2011). Para interpretação do resultado da análise da planta como ferramenta de prognóstico é preciso obter valores referenciais apropriados (Gil et al., 2002). Essa possibilidade é mais factível em culturas irrigadas, onde é menor a probabilidade de ocorrerem problemas após a amostragem das plantas.

Muitas vezes, em planta anual, o diagnóstico é realizado tardiamente, quando não é viável solucionar possível problema. Neste caso, o diagnóstico somente serve para indicar que houve imperfeição no manejo do programa de adubação utilizado, ou seja, tem a função de monitoramento da adubação. É entendido que esse enfoque vem perdendo importância pela variabilidade de resposta que ocorre entre anos.

Como procedimento isolado, o diagnóstico tardio, em plantas anuais, deve ser evitado a menos que seja para a manutenção de um banco de dados local. Também, o diagnóstico tardio do estado de nutrientes da planta pode ser justificável quando realizado anualmente ou em base regular em mesma gleba de planta perene permitindo a criação de um banco de dados específico que poderá tornar o diagnóstico cada vez mais acurado.

\section{Fundamentos do diagnosticador}

O conhecimento vem progredindo, o diagnóstico passa a contar com métodos e procedimentos que empregam não somente o olho, mas cada vez mais incorporando novas tecnologias na forma ou não de algoritmos. Mas, à medida que a tecnologia avança, não é saudável que o profissional se esqueça de pensar. Isto é, não se deve desprezar a tecnologia disponível, mas é fundamental valorizar o conhecimento e o raciocínio lógico, fundamentais na diagnose do estado de nutrientes da planta e no manejo de fertilizantes nas plantas.

Ademais, cuidados são necessários para não haver pressão para a redefinição do que é considerado normal e não serem incorporados procedimentos e exames ainda duvidosos ou não comprovadamente cientifica e monetariamente úteis ao processo de diagnóstico e ao interesse do olericultor. Esquemas rígidos de raciocínio e "procedimentos considerados modernos ou tecnificados ou padronizados" nem sempre são os melhores guias e necessariamente não levarão a melhores resultados do que o comum saber da agronomia, com a especificidade local.

A diagnose é realizada por técnico que tenha postura investigativa e raciocínio lógico. As ações esperadas de um 'diagnosticador' somente são possíveis com profissional motivado, competente e envolvido com limitado número de produtores e de espécie. Esse agente acompanha diariamente a cultura e observa anomalias nas plantas pela comparação com plantios anteriores e com plantas normais na área. Tais condições são fundamentais no processo de diagnóstico.

A tarefa de 'diagnosticador' pode fazer parte das atividades do trabalho de um profissional cada vez mais necessário na atividade agrícola, o agrônomo especialista em nutrição 
mineral de plantas. Dificilmente um visitante esporádico do campo, seja pesquisador, extensionista, agente técnico ou outro profissional será capaz de perceber pequenos anômalos detalhes, às vezes específicos para a variedade, área e tipo de manejo. Os detalhes e o conhecimento permitem ao técnico proceder a sintonia fina dos procedimentos e recomendações disponíveis de forma dispersa e sem especificidade local. No contexto, realizar a sintonia fina é ajustar os procedimentos de manejo do programa de adubação da planta em razão da interação entre ambiente $\mathrm{x}$ solo $\mathrm{x}$ espécie $\mathrm{x}$ interesse do produtor levando-se em consideração exigência do mercado, recurso financeiro disponível, conhecimento técnico-científico existente, sustentabilidade ambiental e padrões éticos e legais vigentes.

Por que diagnosticar o estado de nutrientes de plantas

A resposta é simples: porque há interesse em manejar adequadamente o programa de adubação mineral da cultura. Diversos setores do cotidiano humano podem ser beneficiados pelo manejo específico da adubação. O meio ambiente, pela menor acidificação do solo e eutrofização dos cursos de água. Esse fenômeno provoca a redução do nível de oxigênio (hipoxia) e proliferação excessiva de algas que ao decomporem deterioram a qualidade da água, poluem o lençol freático e salinizam as áreas. $\mathrm{O}$ produtor pode ser beneficiado pela maior produtividade e maior margem de lucro. Os agentes técnicos são beneficiados pela maior eficácia dos insumos vendidos mesmo que não sejam fertilizantes, inclusive informações e, finalmente, os consumidores que poderão dispor de produtos de melhores características organolépticas e de menores preços.

Normalmente há duas situações no contexto de manejo do programa de adubação mineral da cultura visando a produção agrícola. A primeira refere-se à atividade agrícola que é conduzida utilizando-se "normas ou recomendações gerais" não considerando a especificidade da interação genótipo-ambiente-produtor, onde são utilizadas práticas culturais não específicas para aquela situação. Tal atividade agrícola pode ser chamada de 'sistema genérico' ou 'generalista'.

Por outro lado, a segunda situação, como qualquer outra atividade humana, em franca expansão, sem conotação de pequeno ou grande produtor, refere-se à atividade agrícola que é conduzida com a ênfase em tecnologias adaptadas ou ajustadas a cada local, portanto individualizada e com interesse em manejar o programa de adubação considerando a especificidade do local. Nos tempos atuais, as práticas enfocando o uso de tecnologia adaptada a cada local ou tecnologia de aplicação de dose variável ou agricultura de precisão têm sido cada vez mais importantes e buscadas pelos profissionais da agricultura. Pode ser chamado de 'sistema específico'.

Em ambos os sistemas, generalista e específico, a diagnose é feita para confirmar a hipótese que a produtividade ou o desempenho da cultura "aquém do esperado" em determinada área homogênea ou gleba pode ser devida à deficiência ou toxidez (visível ou não) de determinado(s) nutriente(s).

\section{Manejo do programa de adubação}

No 'sistema específico de manejo dos fertilizantes', a função precípua da diagnose é ser uma ferramenta auxiliar na execução da etapa seguinte que é a recomendação do manejo preciso do programa de adubação. Esse sistema é dinâmico, suportado e retro-alimentado por conhecimento, fatos devidamente anotados e relacionados com lógica por profissional que tenha experiência com a cultura e, em maior escala, com a propriedade. Daí, os aplausos às iniciativas do CNPq e FAPEMIG de apoiarem a contratação de mestres e doutores em empresas para permitir e induzir a aproximação entre as empresas privada e entidades de ciência tecnologia e inovação objetivando o desenvolvimento da pesquisa tecnológica e/ou da transferência de tecnologia. Esse parece ser o caminho de uma agricultura tecnificada e "especifica" com o manejo dos fertilizantes continuamente aferido.

Além da diagnose do estado nutricional das plantas, o manejo preciso do programa de adubação das culturas utiliza também, entre outros fatores, de resultados de análise do solo da área onde as plantas foram amostradas, mapas de produção de ‘áreas homogêneas', conhecimentos básicos de agronomia e competência para decidir. No caso do nitrogênio, a análise do solo ainda é questionável sendo necessário enfoque diferente, discutidos em livro do autor (Fontes \& Araújo, 2007).

Apesar das dificuldades, a sintonia fina do programa de adubação da cultura é o desafio do momento e cada vez está sendo mais buscada pelos envolvidos com a agricultura. Neste contexto, é fundamentalmente importante o aprimoramento das técnicas de diagnóstico do estado nutricional de plantas e do agrônomo.

\section{Finalmente:}

É extremamente grande o número de trabalhos, em todas as áreas, buscando entender, adaptar, introduzir e melhorar plantas para ambiente de baixo teor de nutrientes no solo. As tentativas são várias envolvendo solo e planta. É sabido que a regulação dos genes que codificam proteínas de transporte em células de raízes permite às plantas aumentarem a capacidade de aquisição de nutrientes. Embora muitos dos transportadores responsáveis pela aquisição de nutrientes tenham sido identificados, os mecanismos pelos quais os genes transportadores são regulados somente recentemente começaram a ser elucidados (Amtmann \& Blatt, 2009; Miller et al., 2009). Será que em solo de média disponibilidade de nutrientes, o metabolismo da planta será o mesmo que em solo com quase ausência do nutriente (estarvação), pouco comum em solo agricultável?

Entendo que, diminuindo-se as perdas de nutrientes e aumentando-se a produtividade da cultura, via conhecimento e gerência agronômica, aumenta-se a quantidade acumulada do nutriente. Com isso pressiona-se a planta no sentido de mais bem adquirir e utilizar os nutrientes, provavelmente com maior eficiência. Também acredito que haverá equipamentos portáteis que possam "viajar" na área de plantio, no campo, monitorando características biométricas ou biomarcadores das plantas, previamente estudadas e caracterizadas agronomicamente, os quais serão usados para avaliar o estado de nutrientes das mesmas e indicar a necessidade de aplicar dose específica, pontual e eficaz do necessário nutriente (Fontes, 2011). Se 
possível, em uma única operação. Tudo isso acoplado ao avanço na tecnologia computacional e em novos procedimentos de obtenção, catalogação, interpretação e análise de dados, principalmente de imagens.

Avaliando-se as correntes tecnológicas, especialmente as moleculares e de imagens e até onde poderão chegar, Ehrhardt \& Frommer (2012) mencionam algumas tecnologias que poderão transformar a ciência das plantas no século XXI. Esses autores mencionam que, dentre os diversos tipos de tecnologias necessárias no futuro está o estabelecimento de métodos de produzir imagens em profundidade, com nível de resolução super com o objetivo de medir o desempenho da planta. Mais além, a confecção de nanorobôs que possam circular e possibilitar a medição de pontos inacessíveis das células acumulando dados de várias naturezas e grandezas. Também é necessário aprimorar o sensoriamento remoto ou distal do estado nutricional da planta para a tomada de decisão em tempo real sobre o manejo da adubação das culturas (Fontes, 2011).

Uma pergunta que não é minha fica à disposição: será que os cientistas serão capazes de usar a massa de informação que está sendo gerada na detecção e sinalização de deficiências de nutrientes para criar plantas que crescerão melhor em ambientes de baixa disponibilidade de nutrientes mantendo a produtividade em patamar relativamente elevado (Schachtman \& Shin, 2007).

Tenho certeza que a ciência continuará avançando com imensa amplitude envolvendo dezenas de campos de ação, gerando fundamentos teóricos os quais suportarão o progresso da tecnologia de possível utilização pelo olericultor, mesmo que seja de forma lenta, mas cautelosamente ajustada a cada situação pelo agrônomo.

\section{AGRADECIMENTOS}

Ao CNPq e FAPEMIG pelo constante apoio.

\section{REFERÊNCIAS}

AMTMANN A; ARMENGAUD P. 2009. Effects of N, P, K and S on metabolism: new knowledge gained from multi-level analysis. Current Opinion in Plant Biology 12: 275-283.
AMTMANN A; BLATT MR. 2009. Regulation of macronutrient transport. New Phytology 181: 35-52.

CAKMAK I. 2002. Plant nutrition research: Priorities to meet human needs for food in sustainable ways. Plant and Soil 247: 3-24.

CHAPMAN N; MILLER AJ; LINDSEY K; WHALLEY WR. 2012. Roots, water, and nutrient acquisition: let's get physical. Trends in Plant Science 17: 701-710.

CUI X. 2012. Nutrient sensing in plants. Molecular Plant 5: 1167-1169.

EHRHARDT DW; FROMMER WF. 2012. New technologies for $21^{\text {st }}$ Century Plant Science. The Plant Cell 24: 374-394.

FONTES PCR; ARAÚJO C. 2007. Adubação nitrogenada de hortaliças: princípios e práticas com o tomateiro. Viçosa: UFV. 148p.

FONTES PCR. 2011. Nutrição Mineral de Plantas: avaliação e diagnose. Viçosa: Arka. 296p.

GIL PT; FONTES PCR; CECON PR; FERREIRA FA. 2002. Índices SPAD para diagnóstico do estado de nitrogênio e para o prognóstico da produtividade da batata. Horticultura Brasileira 20: 611-615.

GREGORY PJ; NORTCLIFF S. (eds). 2013. Soil conditions and plant growth. Willey-Blackwell Publishing Ltd.. 472p.

HAWKESFORD MJ; BARRACLOUGH P. (eds). 2011. The molecular and physiological basis of nutrient use efficiency in crops. John Wiley $\&$ Sons Inc. 512p.

HERMANS C; HAMMOND JP; WHITE PJ; VERBRUGGEN N. 2006. How do plants respond to nutrient shortage by biomass allocation? Trends in Plant Science 11: 610617.

HIREL B; GOUIS JL; NEY B; GALLAIS A. 2007. The challenge of improving nitrogen use efficiency in crop plants: towards a more central role for genetic variability and quantitative genetics within integrated approaches. Journal of Experimental Botany 58: 2369-2387.

HOEFGEN R; NIKIFOROVA VJ. 2008. Metabolomics integrated with transcriptomics: Assessing systems response to sulfurdeficiency stress. Physiology Plantarum 132: 190-198.

JANICK J. 2008. The tyranny of the impact factor. Chronica Horticulturae 48: 1-3. Disponível em: www.hort.purdue.edu/newcrop/janickpapers/ch4802.pdf Acessado em 25/04/13.

KROUK G; RUFFEL S; GUTIERREZ RA; GOJON A; CRAWFORD NM; CORUZZI GM; LACOMBE B. 2011. A framework integrating plant growth with hormones and nutrients. Trends in Plant Science 16: 178-182.

KUSANO M; FUKUSHI A; REDESTI H; SAITO K. 2011. Metabolomic approaches toward understanding nitrogen metabolism in plants. Journal of Experimental Botany 62: 1439-1453.

MALAVOLTA E. 2008. O futuro da nutrição de plantas tendo em vista aspectos agronômicos, econômicos e ambientais. Informações Agronômicas $\mathrm{n}^{\circ} 121$. SP: IPNI. 24p.

MARSCHNER H. 1995. Mineral nutrition of higher plants. $2^{\text {nd }}$ ed. San Diego: Academic press Inc. $902 \mathrm{p}$.

MARTIN C. 2013. The interface between plant metabolic engineering and human health. Current Opinion in Biotechnology 24: 344353.

MASCLAUX C; QUILLERÉ I; GALLAIS A; HIREL B. 2001. The challenge of remobilisation in plant nitrogen economy. A survey of physio-agronomic and molecular approaches. Annals of Applied Biology 139: 69-81.

MILLER AJ; SHEN Q; XU; G. 2009. Freeways in the plant: transporters for N, P and S and their regulation. Current Opinion in Biotechnology 12: $284-290$.

MONSHAUSEN GB. 2012. Visualizing $\mathrm{Ca}^{2+}$ signatures in plants. Current Opinion in Plant Biology 15: 677-682.

MOUNICOU S; SZPUNAR J; LOBINSKI R. 2009. Metallomics: the concept and methodology. Chemical Society Reviews 38: 1119-1138.

NORTCLIFF S; GREGORY PJ. 2013. The historical development of studies on soil-plant interactions. In: NORTCLIFF S; GREGORY PJ. (eds): soil conditions and plant growth. Blackwell Publishing Ltd. p. 1-21.

PUIG J; PAULUZZI G; GUIDERDONI E; GANTE P. 2012. Regulation of shoot and root development through mutual signaling. Molecular Plant 5: 974-983.

RENGEL Z (ed). 2013. Improving water and nutrient-use efficiency in food production systems. Arnes: Iowa State University Press. $320 \mathrm{p}$.

SALT ED; BAXTER I; LAHNER B. 2008. Ionomics and the study of the plant ionome. Annual Review of Plant Biology 59: 709-733.

SCHACHTMAN DP. 2012. Recent advances in nutrient sensing and signaling. Molecular Plant 5: 1170-1172.

SCHACHTMAN DP; SHIN R. 2007. Nutrient sensing and signaling: NPKS. Annual Review of Plant Biology 58: 47-69.

SILVA AA; DELATORRE CA; MORAES MG. 2011. Ionoma de plantas: cenário atual e perspectivas. Ciência Rural 41: 1390-1397.

URANO K; KURIHARA Y; SEKI M; SHINOZAKI K. 2010. 'Omics' analyses of regulatory networks in plant abiotic stress responses. Current Opinion in Plant Biology 13: $132-138$.

USHA K; SINGH B. 2013. Potential applications of remote sensing in horticulture. Scientia Horticulturae 153: 71-83.

VINOTHKUMARA KR; HENDERSONA R. 2010. Structures of membrane proteins. Quarterly Reviews of Biophysics 43: 65-158.

VON WIRÉN N. 2011. Grand challenges in plant nutrition. Frontiers in Plant Science. Disponível em: <www.frontiersin.org/ Journal/10.3389/fpls.2011.00004/full>. Acessado em: 10/06/2013.

XU G; FAN X; MILLER AJ. 2012. Plant nitrogen assimilation and use efficiency. Annual Review of Plant Biology 63: 153-82. 